A Volunteer Medical Officer Wanted.

On the occasion of the presentation of prizes to the 3rd Essex Volunteers on the 13th inst, at Portway, Lieutenant.Colonel Henry Palmer, 3rd Volunteer Battalion the Essex Regiment, took occasion to mention that no medical gentleman in West Ham had applied for a commission in the 3rd Essex. The 1st Essex had its medical officer, the 3rd Eissex had none.

Volunteer Medical OfFicers and the War OfFice.

A correspondent writes to us under date March 22nd, a letter, in which he propounds the question : Is the Volunteer Medical Service either loyal to the medical profession itself or to the Army Medical Department in doing professional work for nothing? "I am inclined to think," he says, "that the medical officer is decidedly wrong in giving his services to either his country or to individuals for nothing. In the latter case it may be but right that he should retain his individual liberty, but in the former case he has given bimself away, as in a number of corps he pays an annual subscription. Is the profession right in devoting a very considerable part of its time to the working up of bearer companies, each of which occupies the entire attention of at least one medical officer for probably four or five hours a week teaching both by drill and lectures. This year there has been a very important addition made to the duties of medical officersi.e, the examination of recruits. This examination, though not intended to be anything like as thorough as for recruits for the regular forces, still takes some time, and also necessitates the attendance of a medical officer at headquarters weekly."

\section{The Health of the ARMy in Indla.}

Surgeon-Major Whitehead, in the report of the departmental committee on venereal disease, sums up his experience during the five years of his appointment as Assistant Professor of Military Surgery at Netley, during which he had anrivalled opportunities of studying the question of the prevalence of syphilitic disease among our troops, with the following conclusions: "(1) That the disease is more prevalent at present than formerly among foreign invalids; (2) that the type is more malignant ; and (3) that the health and efficiency of the soldier are in many cases absolutely ruined by this disease, and even if he so far recover after a bad attack as to return to duty there is a great probability of his again breaking down." When we consider that this contagious and hereditary disease is largely preventable we may well urge the extreme importance of some measures being taken to put a stop to the present scandalous state of affairs.

Revisted Scales of Pay for the Azmy Medical Staff IN INDIA.

The Times of India of the 6th inst. states that the revised scales of pay approved by the Secretary of State for the Army Medical Staff in India and certain grades of the Indian Medical Service will come into effect from April 1st. An Army circular will shortly be published showing the new arates.

The transport Victoria arrived on the 18 th inst. She brought 320 patients for the Royal Victoria Hospital, Netley.

The transport Dilnara left Bombay on the 11th inst. with 293 invalids for Netley. Her arrival will probably be postponed in consequence of a case of bubonic plague having occurređ̃ on board.

Dr. S. Wilks, President of the Royal College of Physicians, Sir Dyce Duckworth, Sir Wm. Priestley, and Dr. John Anderson visited the Royal Victoria Hospital, Netley, on Saturday last, in connexion with the inquiry which bas been instituted with $r$ gard to the prevention of contagious diseases among the men of the Army in India.

Cardiff Port Sinitary Authority. - The medical officer of health for the Cardiff port sanitary authority has just issued his report for 1896. Dr. Walford estimates the floating population of the port to be 7000 , and states that during the year 6222 vessels were inspected; of these 5271 were in a good or fair condition and 951 in a more or less insanitary state. The systematic inspection of shipping in the Bute and Penarth Docks was efficiently performed by the chief inspector and his assistants. In only fire cases was it necessary to take legal proceedings. Nine patients were admitted to the infectious diseases hospital, one of the cases terminating fatally.

\section{Corregpondente.}

"Audi alteram partem."

\section{"THE MEDICAL STAFFS OF HOSPITALS AND HOSPITAL ABUSE." \\ To the Editors of THE LANCET.}

Sins,-Mr. Horder assumes that I was in error in stating that Sir William Fergusson's committee recommended that medical officers attending the out patients should be paid. I have before me as I write the report of the committee appointed to inquire into the subject of Out-patient Hospital Administration in the Metropolis in 1871, signed by Alfred Meadows, M.D., chairman, J. H. Stallard, M.B., and Hey wood Smith, M.B., honorary secretaries. The report states: "The following resolutions embody in brief form the conclusions at which your committee have arrived and which they recommend for adoption." No. 6 of these resolutions runs as follows: "That the governors of hospitals ought in all cases to provide some honorarium for the staff of the out-patient department." You w1ll see, therefore, that $\mathbf{M r}$. Horder, and not myself, is in error, and I am rather surprised to find that he has not procured a copy of the report in question, and that he is evidently not familiar with its terms.

On another point raised by $\mathrm{Mr}$. Horder I desire to impress upon the medical profession that so long as we have honorary medical staffs attached to our great hospitals-that is, unpaid staffs-so long will the hands of the managing committees be tied, so far as initiative is concerned, in the work of reforming the out-patient departments unless the medical profession commence proceedings by making representations to the managers. This fact makes me strongly in favour of the abolition of all honorary medical service, at any rate so far as the great London hospitals are concerned. I am sure on the grounds of economy. although it might cost the hospitals $£ 60,000$ a year to pay for the necessary medical service, such a step would in the end tend to reduce rather than to increase the average cost per bed. The medical profession now have a unique opportunity, which may not recur, of conferring together and formulating a definite policy in regard to out-patient relief and other matters of pressing importance affecting the administration of our hospitals. I wrote my letter because I realised this position of affairs, and wished, if possible, to induce the medical profession in its own interests, and in the best interests of the hospitals and all connected with them, to take up a strong position after due deliberation and conference by formulating a policy in regard to these matters. The governors and committees would thus be placed in a position to institute every reform. which may be found desirable or necessary in the best interests of the patients, the profession, and the public. I desire to thank Mr. Horder, and through him the member. of his committee, for their statesmanlike determination to postpone for a time the public conference which it was pro posed to hold this summer.

The writer of the leading article in THE LANCET of March 20th, no doubt unintentionally, does me less than justice. I have never stated, nor do I hold the opinion, that "the Hospital Sunday Fund and the Prince's Fund have at present but little responsibility for the use of what they collect." On the contrary, it is because I am deeply impressed with the responsibility attaching to the distribution of these funds, and to the paramount necessity of providing that our voluntary charities shall be as free, as it is humanly possible to make them, from all preventable abuses, that I ventured to write you the letter which appeared in THE LANCET of March 13th, and to state the grounds upon which I gave my entire support to your proposal, that a conference should take place in the near future of the members of the honorary medical staff, attached to every hospital of repute in the metropolis. I joined issue with Dr. Glover on the out-patient question, so far as the Hospital Sunday Fund was concerned, because I realise, that without such a conference not only the Hospital Sunday Fund, but the hospital committees throughout London, must remain practically powerless to enforce the reforms in the out-patient departments, which he has so much at heart. Premature action and an attempt at interference without the necessary authority to enforce needful reforms, are calculated to prove 
more harmful than helpful. That is why I ventured to deprecate putting the cart before the horse, by moving the Hospital Sunday Fund to make representations, before we were clear that those representations could be accepted by the hospital committees with the support of their medical staffs; for with the medical staffs, as I have already stated, the chief responsibility for the present state of affairs in reality rests. I am, Sirs, your obedient servant,

The Lodge, Porchester-square, W., March 22nd, 1897. HENRY C. BURDETT.

\section{To the Editors of THE LANCET.}

SIRS,-With reference to the letter of Mr. T. Garrett Horder in THE LANCET of March 20th I should be obliged if you would allow me to say that at this hospital we have for many years made inquiries into the circumstances of the out-patients. May I also add that a medical officer sifts the cases before they are seen by the assistant physician or assistant surgeon.

I am, Sirs, yours faithfully, C. L. TODd, Secretary.

St. George's Hospital, S.W., March 24th, 1897.

\section{"HOSPITAL ABUSE: THE LEEDS WORK- PEOPLE'S HOSPITAL FUND."}

To the Editors of THE LANCET.

SiRs,-As a general practitioner of medicine for seventeen years in Leeds, during which time I have seen a great deal of the working-man patient, also having as a student attended at the Leeds Infirmary, I have arquired some little experience in the subject discussed by THE LANCET Commissioner, which experience is directly opposed to that of Dr. Eddison and to that of Mr. Jowitt. The working man, I believe, subscribes to the infirmary $1 d$. a week, or something like $4 s$. per year. Now, very few lodges pay per head so much as that for medical and surgical attendance-the club patient can for the sum of $3 s .6 d$. per annum command attendance at his own home and medicine, \&c. Naturally he supposes that the larger amount paid to the infirmary gives him equal rights at that institution, and I have heard this said not once but often, so often, indeed, that I was astonished that any one should make an assertion to the contrary. I have known the case of a woman possessed of independent means, able to pay 50 guineas for a surgical operation, become an in-patient of the Leeds Infirmary for the purpose of an operation; she was not a resident in Leeds, she had no claim upon Leeds, and the surgeon who performed the operation robbed himself of something like 50 , or it may easily have been 100 , guineas. Moreover, her friends considered her as a private patient and so termed her. In another town a lady of fortune, who spends large sums in charity, fell from a bicycle, costing probably $£ 30$, breaking her leg. She was treated in an infirmary, to which institution she presented $£ 100$ on leaving, which money I affirm was rightfully the fee of some practitioner, though perhaps no medical man would have had such a large amount of gratitude shown to him. I have known a man treated at the Leeds Infirmary for fractured arm throughout the entire course, which man lived in a good house in a good neighbourhood-such a district, in fact, where all consulting surgeons and physicians ask for fees on the higher scale. In my student days I actually extracted teeth from people I knew could afford a dentist's fees. Little, perhaps, they knew it was a 'prentice band that held the forceps! I have known a woman in good circumstances leave her rings and jewellery at home, so advised to do by her friends, when it was necessary to consult a leading Leeds surgeon at his rooms-nay, more, she dispensed with her brougham, using the humble cab; and this course was adopted to save one guinea, the idea being that she would be charged two guineas if she appeared in her proper guise. The sufferers from trivial accidents requiring minor surgical operations are all urged to go to the infirmary. Persons even spend more in railway and cab fares than would be charged by ordinary medical men. It is obvious that those who will so spend from $2 s$. $6 d$. to $5 s$. are not those for whom a charitable institution is intended. I suppose all who subscribe-in the way of rates, at least-to the Leeds Workhouse bave the right to claim a place there. Then why deny those who subscribe to the Leeds Infirmary the same rights? Buth of these institutions are for the poor and sick. I do not wish my name and address to appear.

I am, Sirs, yours truly,

Leeds Practitioner.

\section{"THE MIDWIVES REGISTRATION BILL." To the Editors of THE LANCET.}

Sirs,--May I point out that your correspondent who writess anenymously in favour of registration in TIIE LANCET of March 20 th is extremely wide of the mark. He thinks, like the promoters of the Bill, that the magic of registration will efface the horrors he describes and, like Dr. Culling worth, that. the maladies of childbirth will cease to be ; in fact, that we are on the eve of a parturient millennium. One of the staple. arguments of registrationists is that the educated midwife. will send for medical aid on the first approach of danger. This is a mere supposition. The "follower" of one of these women in this parish was required in 23 per cent. of her cases in 1892 , and in $82,2 \cdot 5,27$, and 28 per cent. in 1893,1894 . 1895, and 1896 respectively. One woman died in her confinement, there was a death from miscarriage, and an infant was sacrificed through delay in a shoulder and funis presentation. I need not add to the list of casualties; and will only say, in conclusion, that a Bill which proposes to register bon $\hat{a}$ fid $\bar{t}$ midwives of two years' standing, which will include most of the existing "Gamps" and which still recognises the friendly neighbour's assistance, stands self-condemned. There is no provision at all for the after-nursing, which is the most vital part of the parturient function, and as it is perfectly evident that the qualified midwife will not act as an obstetric nurse under medical supervision I utterly fail to see how the Bill will benefit "the poor" if it become law; and if I had not had the promise of Mr. Skewes-Cox to have it referred to a com-... mittee of the Honse so that "all parties" may be heard I would long ago bave offered it a more vigorous opposition. Dr. Cullingworth is a special pleader, and his recent address on puerperal fever is largely discounted by his attitude in this question and his more recent address to the promoters of the measure.-I am, Sirs, yours faithfully,

East Sheen, March 22nd, 1897.

ALEX. MCCOOK WeIR.

\section{THE COLONY FOR EPILEPTICS. To the Editors of THE LANCET}

StRs, - Will you allow us to make an appeal through the columns of THE LANCET on behalf of the colony established at Chalfont St. Peters by the National Bociety for Employment of Epileptics. Amidst the earnest efforts for the succour of the sick and afflicted which have so distinguished this country during Her Majesty's reign. one form of infirmity is still almost overlooked, and in England there are probably not less than 40,000 epileptics who lack the care which is bestowed upon their fellow sufferers amongst other nations. For both in Europe and America many institutions or settle. ments have been established on the lines of the famous "Colony of Mercy" at Bielefeld, in Westphalia, which affords a home for nearly 1400 epileptics. Under ordinary circumstances epileptics of the poorer classes live under conditions so unsuitable that in many instances they sink: into a state of insanity and at last find refuge in the asylums. The object of the colony is to save them from this fate by taking them in hand at an earlier stage and enabling them to lead lives of usefulness and activity. The care of the insane is a heary burden on the country, and the preventive methods of the culony will, we believe, be found in the long. run to be economic as well as humane.

Amongst the numerous candidates waiting for admission to the colony, about one in ten drops out of the list every year through insanity or death, whilst at the colony itself, since its establishment nearly three years ago, only one death has occurred and only one patient has had to be transferred to an asylum. The average number of epileptics in residence at the colony has been twenty-seven. Besices the two homes at present in occupation at the colony, two others, the funds for which have been specially given, are in course of erection, and additional funds have been offered by generous friends, notably by Mr. Passmore Edwards, for the erection of several other bomes, which will be commenced shortly. Within a year there will therefore, it is hoped, be accommodation at the colony for about 160 epileptics, men, women, and children. Even then the provision will be small in comparison with the need. But while the funds for building the new homes are provided, these great extensions will involve considerable 